\title{
Benefícios da drenagem linfática manual no pós operatório de cirurgias plásticas
}

\author{
Benefits of manual lymphatic drainage in post-operative plastic surgery \\ Beneficios del drenaje linfático manual en post-operatorio de cirugías plásticas
}

Recebido: 03/12/2021 | Revisado: 08/12/2021 | Aceito: 11/12/2021 | Publicado: 19/12/2021

\author{
Ariane Freire Soares \\ ORCID: https://orcid.org/0000-0002-9586-0550 \\ Faculdade Independente do Nordeste, Brasil \\ E-mail: ariane.freire.soares@gmail.com \\ Jeane Rocha Santos \\ ORCID: https://orcid.org/0000-0002-1398-3638 \\ Faculdade Independente do Nordeste, Brasil \\ E-mail:Jeane@fainor.com.br
}

\begin{abstract}
Resumo
A procura por cirurgias plásticas cresce consideravelmente, a técnica visa modelar as estruturas normais do corpo, o procedimento é invasivo e necessita de preparo pós cirúrgico, com isso, a modalidade da drenagem linfática manual faz-se necessária a fim de auxiliar nas alterações vasculares e no edema local, sendo indicado na fase aguda do pós operatório, executada através de leves movimentos. O objetivo desta pesquisa é descrever através de literaturas já existentes os benefícios da drenagem linfática manual no pós-operatório de cirurgias plásticas. Trata-se de uma revisão de literatura, com o intuito de construir novos contextos acerca da temática através de outras literaturas examinadas em plataformas online, como critério de exclusão artigos que não se adequaram ao ano e tema de pesquisa. Na base de buscas foram encontrados estudos de revisão bibliográfica, onde retrata a importância da drenagem linfática manual no pós operatório de cirurgias plásticas, retratando melhora no quadro de edemas, circulação periférica e amenizando os riscos de intercorrências após a cirurgia, além disso, melhora a saúde mental do indivíduo que se submeteu a plástica corporal. Conclui-se que a drenagem linfática manual possui inúmeros benefícios aplicada no pós operatório de cirurgias plásticas, apresenta melhora no sistema físiológico como um todo, para o reparo do tecido lesado após o procedimento invasivo, sendo necessário novos estudos relacionado com o tema para elaboração de protocolos seguros e eficientes.
\end{abstract}

Palavras-chave: Drenagem linfática; Cirurgia plástica; Pós operatório.

\begin{abstract}
The demand for plastic surgery grows considerably, the technique aims to model the normal structures of the body, the procedure is invasive and requires post-surgical preparation, with this, the modality of manual lymphatic drainage is necessary in order to assist in vascular changes and in local edema, being indicated in the acute phase of the postoperative period, performed through light movements. The objective of this research is to describe through existing literature the benefits of manual lymphatic drainage in the postoperative period of plastic surgery. This is a literature review, in order to build new contexts on the subject through other literature examined in online platforms, as an exclusion criterion articles that did not fit the year and research topic. In the search base, literature review studies were found, which portray the importance of manual lymphatic drainage in the postoperative period of plastic surgery, portraying an improvement in the condition of edema, peripheral circulation and alleviating the risks of complications after surgery, in addition, improving the mental health of the individual who underwent body plastic surgery. It is concluded that manual lymphatic drainage has numerous benefits applied in the postoperative period of plastic surgeries, it presents an improvement in the physiological system as a whole, for the repair of the injured tissue after the invasive procedure, requiring further studies related to the topic for the elaboration of safe and efficient protocols.
\end{abstract}

Keywords: Lymphatic drainage; Plastic surgery; Post operative.

\section{Resumen}

La demanda de cirugía plástica crece considerablemente, la técnica tiene como objetivo modelar las estructuras normales del cuerpo, el procedimiento es invasivo y requiere preparación posquirúrgica, con esto, la modalidad de drenaje linfático manual es necesaria para ayudar en los cambios vasculares y en el edema local, estando indicado en la fase aguda del postoperatorio, realizado mediante ligeros movimientos. El objetivo de esta investigación es describir a través de la literatura existente los beneficios del drenaje linfático manual en el postoperatorio de cirugía plástica. Se trata de una revisión de la literatura, con el fin de construir nuevos contextos sobre el tema a través de otra literatura examinada en plataformas en línea, como criterio de exclusión de artículos que no se ajustan al año y tema 
de investigación. En la base de búsqueda se encontraron estudios de revisión de la literatura, que retratan la importancia del drenaje linfático manual en el postoperatorio de cirugía plástica, retratando una mejora en la condición de edema, circulación periférica y aliviando los riesgos de complicaciones postoperatorias, además, mejorar la salud mental del individuo que se sometió a una cirugía plástica corporal. Se concluye que el drenaje linfático manual tiene numerosos beneficios aplicados en el postoperatorio de cirugías plásticas, presenta una mejora en el sistema fisiológico en su conjunto, para la reparación del tejido lesionado luego del procedimiento invasivo, requiriendo más estudios relacionados con el tema. para la elaboración de protocolos seguros y eficientes.

Palabras clave: Drenaje linfático; Cirugía plástica; Postoperatorio.

\section{Introdução}

De acordo com a Sociedade Brasileira de Cirurgia Plástica (2011), a modalidade estética é um tipo de cirurgia plástica que tem como objetivo promover o remodelamento das estruturas normais do corpo no intuito de melhorar a aparência e autoestima dos pacientes. O Brasil é um dos países que mais realizam cirurgias, com uma estimativa de 629 mil cirurgias plásticas por ano, sendo 69\% destas estéticas. Segundo Borges (2006), o ato cirúrgico promove uma agressão ao tecido cutâneo, que, mesmo bem realizado, pode lesá-lo.

De acordo com Guirro\&Guirro, inicia-se o tratamento pós operatório já na fase aguda. Neste sentido, a drenagem linfática trata-se de uma técnica que auxiliará no tratamento das alterações vasculares inerentesa fase inicial, o edema. Entretanto,deve-se levar em consideração que a cicatrização ainda está recente, sendo assim, a técnica deve ser aplicada suavemente para evitar deslizamentos e trações no tecido que está em fase cicatricial.

De acordo Verner (2010), a drenagem linfática manual é uma das técnicas e métodos mais realizados no pósoperatório. A técnica está totalmente relacionada ao sistema linfático, que se trata do sistema de drenagem do nosso organismo. A realização das manobras devem ser: lentas, suaves, e precisas, respeitando os aspectos da drenagem linfática, promovendo uma melhora no tecido e na cicatrização. Guirro\&Guirro (2002) afirmam que a Drenagem Linfática Manual (DLM) trata-se de uma técnica de mobilização da linfa quereabsorve o acúmulo de líquidos intersticiais e ativa a motricidade dos vasos linfáticos, o que leva a melhora da oxigenação local e da circulação dos tecidos, além de aceleraro processo de cicatrização e absorver os hematomas.

Segundo Guirro e Guirro (2002), a pressão exercida durante a drenagem é capaz de captar o excesso de líquido, com o objetivo de atenuar as chances de fibrose, tirando o líquido do meio tissular e levando para os vasos linfáticos e venosos, e desta forma, manter o equilíbrio das pressões tissulares e hidrostáticas.O tratamento inicia-se na fase aguda, porém, devido ao processo de cicatrização, a aplicação da técnica deve ser o mais suave possível, evitando deslizamentos e trações no tecido (Guirro\&Guirro, 2002).

O objetivo desta pesquisa é descrever os benefícios da drenagem linfática manual no pós operatório de cirurgias plásticas.

\section{Metodologia}

O presente estudo trata-se de uma revisão de literatura que assume dois objetivos: Construir a contextualização de um problema e a analisar a alternativas existentes na literatura examinadas para a criação do referencial teórico da pesquisa. Ainda assume o aspecto de um uma pesquisa descritiva exploratória, por se tratar tema pouco estudado, ou explorado (Gil, 2010). Foram selecionados 50 artigos nas bases de dados, Sielo, Pubmed/ Medline e PsychINFO, utilizando os descritores "Drenagem Linfática Manual" E "pós cirúrgico de cirurgias plásticas", através da leitura da revisão e da introdução dos mesmos. Como critérios de inclusão foram escolhidos os artigos que apresentaram relação com o tema estudado e com datas de publicação entre os anos de 2010 a 2020. Os critérios de exclusão adotados foram: não foram aceitos artigos que não tinham relação com a temática, ou datados anteriormente ao ano de 2009. Após análise, os artigos escolhidos foram organizados em 
uma tabela que continha subdivisões: título, autor e ano, objetivos, métodos e resultados. Também foi feita uma análise descritiva e comparativa dos dados acumulados sobre o tema, pois desta forma, a abordagem da temática ficou mais explícita e objetiva. O estudo seguiu os aspectos éticos dispostos na Lei de Direitos Autorais: Lei número 9.610, de fevereiro de 1998. As referências foram completas a ponto de permitir que outras pessoas possam ter acesso às mesmas e garantir autenticidade e fidedignidade das informações utilizadas.

\section{Resultados e Discussão}

Dentre as 20 publicações selecionadas para esse estudo, cada autor demostra, com suas particularidades, que a técnica de drenagem linfática manual tem aplicabilidade importante no pós-operatório de cirurgias plásticas. O quadro abaixo traz informações acerca dos dados das pesquisas. Para melhor compreensão, os dados dos artigos foram organizados em um quadro - Quadro 1, contendo informações referentes ao ano de publicação, título, autor e ano de publicação, objetivos, métodos e principais resultados de cada artigo selecionado.

Quadro 1 - Artigos segundo, título, autores e ano de publicação, objetivos, métodos e principais resultados. Vitória da Conquista, Bahia, Brasil. 2021.

\begin{tabular}{|c|c|c|c|c|}
\hline Título & Autor/Ano & Objetivos & Métodos & Resultados \\
\hline $\begin{array}{l}\text { Complicações em } \\
\text { cirurgias prevenção e } \\
\text { tratamento: } \\
\begin{array}{l}\text { Complicações } \\
\text { cirurgia da mama. }\end{array}\end{array}$ & $\begin{array}{l}\text { Costa et al. } \\
(2021)\end{array}$ & $\begin{array}{l}\text { Verificar o efeito da } \\
\text { drenagem linfática manual } \\
\text { na redução da dor e das } \\
\text { complicações existentes no } \\
\text { pós-operatório } \\
\text { mamoplastia }\end{array}$ & $\begin{array}{l}\text { Revisão } \\
\text { bibliografica }\end{array}$ & $\begin{array}{l}\text { A drenagem linfática manual melhora as funções } \\
\text { do sistema circulatório linfático. auxiliando no } \\
\text { processo de cicatrização, melhora a textura e } \\
\text { elasticidade da pele, diminuindo os edemas } \\
\text { causados pela cirurgia, restabelecendo a corrente } \\
\text { circulatória periférica da lesão, agindo de maneira } \\
\text { reabilitadora e preventiva, desta forma } \\
\text { diminuindo a incidência dos problemas de } \\
\text { contratura capsular e demais complicações da } \\
\text { cirurgia de mamoplastia de aumento. }\end{array}$ \\
\hline $\begin{array}{l}\text { A Atuação da } \\
\text { Fisioterapia no Pré e } \\
\text { Pós Operatório De } \\
\text { Cirurgia Plástica } \\
\text { Corporal: Uma } \\
\text { Revisão De Literatura. }\end{array}$ & $\begin{array}{l}\text { Macedo A. C.B.; } \\
\text { Oliveira } \\
\text { M(2011) }\end{array}$ & $\begin{array}{l}\text { Realizar uma revisão } \\
\text { bibliográfica a respeito da } \\
\text { abordagem fisioterapêutica } \\
\text { no pré e pós operatório de } \\
\text { cirurgia plástica. }\end{array}$ & $\begin{array}{l}\text { Revisão } \\
\text { bibliográfica }\end{array}$ & $\begin{array}{l}\text { No tratamento pré e pós-operatório de cirurgia } \\
\text { plástica, é importante o processo de interação } \\
\text { entre os fisioterapeutas e cirurgiões plásticos, } \\
\text { visando a minimizar intercorrências, para uma } \\
\text { boa evolução pós-operatória. }\end{array}$ \\
\hline $\begin{array}{l}\text { Os Benefícios da } \\
\text { Drenagem Linfática } \\
\text { Pós Mastectomia. }\end{array}$ & $\begin{array}{l}\text { Prado et al. } \\
(2020)\end{array}$ & $\begin{array}{l}\text { Descrever os benefícios da } \\
\text { drenagem linfática no pós } \\
\text { operatório de mastectomia }\end{array}$ & $\begin{array}{l}\text { Revisão } \\
\text { integrativa da } \\
\text { literatura }\end{array}$ & $\begin{array}{l}\text { A drenagem linfática e os outros tratamentos } \\
\text { terapêuticos, diante das sequelas deixadas pelo } \\
\text { tratamento da mastectomia, traz uma melhor } \\
\text { qualidade de vida para o paciente, tanto questões } \\
\text { que afetam o físico e o emocional. }\end{array}$ \\
\hline $\begin{array}{l}\text { Os benefícios da } \\
\text { drenagem linfática no } \\
\text { pós-operatório de } \\
\text { cirurgias plásticas. }\end{array}$ & $\begin{array}{l}\text { Matoso, Karoline } \\
\text { \&Benati; Maria } \\
\text { (2019) }\end{array}$ & $\begin{array}{l}\text { Apresentar os benefícios da } \\
\text { drenagem linfática no pós- } \\
\text { operatório de cirurgias } \\
\text { plásticas }\end{array}$ & $\begin{array}{l}\text { Revisão } \\
\text { bibliografica }\end{array}$ & $\begin{array}{l}\text { Percebeu-se que a drenagem linfática é de } \\
\text { extrema importância no pós-cirurgia, } \\
\text { principalmente em cirurgias plásticas, trazendo } \\
\text { benefícios na recuperação do paciente em vários } \\
\text { aspectos. }\end{array}$ \\
\hline $\begin{array}{l}\text { Drenagem linfática no } \\
\text { pós-operatório em } \\
\text { abdominoplastia }\end{array}$ & $\begin{array}{l}\text { Batista, Eliete; } \\
\text { Nejia, Dayana } \\
(2015)\end{array}$ & $\begin{array}{l}\text { Realizar uma revisão } \\
\text { bibliográfica a respeito da } \\
\text { importância e benefícios da } \\
\text { drenagem linfática manual } \\
\text { no pós-operatório em } \\
\text { abdominoplastia. }\end{array}$ & $\begin{array}{l}\text { Revisão } \\
\text { bibliografica }\end{array}$ & $\begin{array}{l}\text { A drenagem linfática é uma técnica embasada em } \\
\text { conceitos científicos e pode ser usada no } \\
\text { tratamento pós-operatório de cirurgias plásticas } \\
\text { reparadora, ajudando diretamente na eliminação } \\
\text { das toxinas, diminuindo edemas, deiscências, } \\
\text { fibroses e cicatrizes. }\end{array}$ \\
\hline
\end{tabular}

Fonte: Autores.

De acordo com Cardozo et al. (2016), em geral, posteriormente a algumas cirurgias plásticas estética, a equipe médica, recomenda a realização de drenagem linfática manual, com o objetivo de diminuir os desconfortos e sinais clínicos como 
edemas e ajudar no processo de cicatrização. A técnica foi criada em 1936, pelo médico dinamarquês Dr. Emil Voddere era considerada como uma terapia de apoio. Entretanto, logo mais, passou a ser considerada um padrão ouro para o tratamento de linfedema.

Para Macedo e Oliveira (2011), o papel da equipe multidisciplinar é fundamental, valorizando a interação entre os profissionais da estética e cirurgiões plásticos, visando a minimizar intercorrências, para uma boa evolução pós-operatória. O estudo de Prado et al 2020) avalia também os benefícios psicossociais da drenagem linfática, diante das sequelas deixadas pelo tratamento da mastectomia, como, melhora da qualidade de vida para o paciente.

De acordo com Borges (2006), a drenagem linfática (DL) atua positivamente na recuperação do paciente, ajudando na: cicatrização eprevenção de novas intercorrências, por estimular o fluxo linfático. Através das manobras e da pressão exercida pelo profissional, a mobilização da linfa é ativada, o que minimizaos efeitos da cirurgia e reduz o edema.

O artigo de Costa et al. (2021) aborda meios para prevenção de complicações cirúrgicas, entre esses, enfatiza a drenagem linfática manual, que melhora as funções do sistema circulatório linfático, auxiliando no processo de cicatrização, melhora a textura e elasticidade da pele, diminuindo os edemas causados pela cirurgia, restabelecendo a corrente circulatória periférica da lesão, agindo de maneira reabilitadora e preventiva, desta forma diminuindo a incidência dos problemas de contratura capsular e demais complicações da cirurgia de mamoplastia de aumento.

De acordo com Ozolins et al (2018), a drenagem linfática de ser iniciada através dos estímulos dos linfonodos, seguida de movimentos de escoamento para a linfa. São realizadas intervenções com pressão leve e ritmo lento, acompanhando a direção da circulação sanguínea e fluxo linfático, de proximal para distal, de modo a não congestionar o sistema. Matoso \&Benati (2019) descreveram a drenagem linfática como uma técnica de massagem leve que não causa dor nem hematoma estimulando o sistema linfático a trabalhar mais rápido, eliminando toxinas, levando mais nutrientes as células e melhorando o aporte sanguíneo. O principal objetivo em pacientes que se submetem a mamoplastia é a regularidade e normalização da circulação linfática (Nunes, 2018). Em mastectomias a drenagem é feita de forma reversa, pois geralmente em cirúrgicas plásticas, existem a interrupção dos vasos linfáticos e isso irá impedir que aconteça a drenagem linfática manual clássica (Matoso \&Benati, 2019).

As intercorrências podem ser diminuídas pelos efeitos da drenagem linfática manual. Os seromas, por exemplo, são manifestações tardias sem causa definida que pode até mesmo implicar na remoção ou troca das próteses (Franco\& Franco, 2012), a drenagem linfática realizada por um profissional capacitado, pode assim, evitar tais complicações, pois evita a estase linfática (Ribeiro, 2013).A técnica manual no pós-operatório possibilita também benefícios como a diminuição de nodulações fibróticas no tecido subcutâneo, minimização de possíveis aderências teciduais, cicatrização, redução das áreas com hipoestesias, redução de hematomas e equimoses, melhora a circulação e o tônus muscular (Batista\&Mejia, 2015).

Guimarães, et al. 2015, realizou uma pesquisa em que utilizou a DLM no pós operatório de abdominoplastia que confirmou a eficácia na reabsorção do líquido intersticial e por consequência reabsorção do edema residual e melhora do pós cirúrgico.

No estudo sobre a DLM no pós-operatório imediato de cirurgia vascular foi amenizado a formação do edema, aparência mais saudável e normal da pele, ocasionando a melhora na oxigenação e nutrição celular, reduzindo os hematomas procedentes do processo cirúrgico. A DLM também realizou um papel importante na compensação das incisões, dando início a uma barreira protetora das lesões contribuindo ainda mais no processo de cicatrização (Alencar, et al., 2011).

\section{Considerações Finais}

Diante do exposto, conclui-se que a drenagem linfática manual possui inúmero benefícios quando aplicada no pós operatório de cirurgias plásticas, uma vez que possui efeitos importantes, tais como: melhora do sistema imunológico e a 
circulação sanguínea e linfática, bem redução do edema, diminuição e prevenção de aderências, reconstituição da corrente circulatória periférica da lesão, fazendo de maneira reabilitadora e preventiva, proporcionando assim bem-estar e melhoria da saúde a todos os níveis.

O trabalho do esteticista juntamente com uma equipe multidisciplinar ajudará na recuperação da paciente, melhora de complicações e na cicatrização da ferida operatória.

Ressalta-se ainda a importância de novos artigos relacionados com o tema que possam ajudar os profissionais a elaborarem protocolos seguros e eficientes com a utilização da drenagem linfática manual no pós operatório das cirurgias plásticas.

\section{Referências}

Batista, E., Mejia, D. (2015). Drenagem linfática no pós-operatório em abdominoplastia. Biocursos Manaus- FACOPH.

Brandão, D. S. M. et al. (2010) Avaliação da técnica de drenagem linfática manual no tratamento do fibro edema geloide em mulheres. Sistema de Información Científica.

Alencar, Tatiana Priscila De; Meja, Dayana Priscila Maia. (2011). A influência da drenagem linfática manual em pós-operatório imediato de cirurgia vascular de membros inferiores. Bio Cursos.

Guimarães, Thais Dutra De, Isadora AroinsSodre, Adriane Bertotto. (2015) Drenagem linfática manual associada ao pós operatório de abdominoplastia: um estudo de caso. Unilasalle.

Cantinelli, F. S., Camacho, R. S., Smaletz, O., Gonsales, B. K., Braguittoni, E., Rennó, J. R. (2011). A oncopsiquiatria no câncer de mama: considerações a respeito de questões do feminino. RevPsiquiatrClín.; 33(3): 124-33.

Cerdeira, Denilson de Queiroz. Et al. (2014) Atuação fisioterapêutica em pacientes pós-cirurgia do câncer de mama: uma revisão bibliográfica. Revista Expressão Católica. V03, n01. 23-35.

Corrêa, Luiz. Eduardo. Grossi, Cássio Del. (2018). A eficácia da drenagem linfática manual em pacientes pós- cirúrgicos de mastectomia. Faculdade Apucarana.

Costa, M. M.; Lima, C. F. F; Da Silva, S. S. C., BErgmann, A. (2021) Complicações em cirurgias prevenção e tratamento: Complicações da cirurgia da mama. Colégio Brasileiro de Cirurgiões. DOI: 10.1590/0100-6991e-2021EDIT01

Luz, N. D., Lima, A. C. G. (2011). Recursos fisioterapêuticos em linfedema pós mastectomia: uma revisão de literatura. Fisioter Mov. Curitiba, v. 24, n. 1, p. 191-200.

Macedo, A. C. B; Oliveira, S. M. (2021). A Atuação da Fisioterapia no Pré e PósOperatório De Cirurgia Plástica Corporal: Uma Revisão De Literatura. Cadernos da Escola de Saúde. Curitiba: v.5, p. 169-189.

Marchon, R. M., Ferreira, M. de F. B., Dias, R. A., et al. (2016). Influência do apoio social na resposta terapêutica do linfedema de membro superior após o câncer de mama. v 26, n 3. Rio de Janeiro.

Matoso, K., Benati, M. (2019). Os Benefícios Da Drenagem Linfática No Pós-operatório De Cirurgias Plásticas. Rev. Saberes, Rolim de Moura, v. 9, n. 1.

Ozolins, B. C., Mendes, A. F. G.; Pinto, L. P.; Assis, I. B. (2018) Drenagem linfática clássica - revisão de literatura. Revista saúde em foco. n 10. p. 319-323.

Prado, A. S. et al. (2020). Os benefícios da drenagem linfática pós mastectomia. Id Online Rev. Mult. Psic. v.14, n. 52, p. 362-373.

SBCP - MG. (2021). Sociedade brasileira de cirurgia plástica de minas gerais. Associação médica brasileira.

Silva, P. A., Riul, S. S. (2021) Câncer de mama: fatores de risco e detecção precoce. Rev. Bras. Enferm. Brasília, p.1016-21.

Smeltezer, S. C., Bare, B. G., Hinkle, J. L., Cheever, K. H. (2009). Tratado de enfermagem médico. Cirúrgica. Rio de janeiro.

Táboas, Maria Inês. Torres, Ana. Popik, Igor. Casalta, Paulo. Lima, Luís. Caldas, Jorge. (2013) Linfedema: revisão e integração de um caso clínico. Revista da Sociedade Portuguesa de Medicina Física e de Reabilitação. v. 23. n. 1, p 70-78.

Tacani, P. M; Machado, A. F. P., Tacani, R. E. (2012). Abordagem fisioterapêutica do linfedema bilateral de membros inferiores. Rev. Fisioterapia mov.

Vasconselos, Ana. Paula. Braga. Ribeiro, Francilene Gonçalves.; Torres, MillyWeslany Carvalho de. (2012). Câncer de mama: mastectomia e suas complicações pós-operatórias - um enfoque no linfedema e na drenagem linfática manual/ dlm.

Verner, R. S. A. (2010). Drenagem linfática manual pós mamoplastia de aumento. 